\title{
The Work-Family Interface of Service Sector Workers. A Comparison of Work Resources and Professional Status across Five European Countries*
}

\author{
Barbara Beham, Sonja Drobnič, and Patrick Präg
}

2014

\begin{abstract}
The present paper examines cross-national differences in the utilisation of work-family resources at the organizational level and the relationships between these resources and work-to-home interference (WHI) and satisfaction with work-family balance (SWFB) among professional and non-professional service sector employees in five Western European countries. Further, it explores cross-national variations in the gap between professionals and non-professionals with respect to both outcome variables. Professional service sector employees were consistently found to experience higher levels of WHI and lower levels of SWFB. The use of organizational work-family resources differed across welfare state regimes and levels of national gender equality. It was highest in Sweden and The Netherlands and lowest in Portugal. A family-supportive supervisor and a family-supportive organizational culture differentially affected WHI of professional and non-professional workers, with a family-supportive supervisor being more beneficial to non-professionals and a family-supportive organizational culture being more beneficial to professional employees. Finally, the gap between professionals and non-professionals was also found to vary across countries for WHI but not for SWFB. It was significantly larger in the United Kingdom and in Sweden than in the other three countries.
\end{abstract}

*Published in 2014 in Applied Psychology 63(1), pp. 29-61, doi:10.1111/apps.12012.

Research for this study was partly supported by the European Commission through funding from the cross-national collaborative research project 'Quality of Life in a Changing Europe' (Bäck-Wiklund et al., 2011), within which the data were collected. The authors would like to thank co-researchers in the project as well as the guest editors and three anonymous reviewers for very helpful comments on earlier drafts of this paper. 


\section{Introduction}

The reconciliation of work and family life has attracted a lot of scholarly attention in recent decades. A substantial body of research has examined the antecedents and consequences of work-family conflict (see Eby et al., 2005; Michel et al., 2011, for an overview), which is defined as a type of inter-role conflict that occurs when the role demands of the work domain interfere or are incompatible with family demands (Greenhaus and Beutell, 1985). More recently, the field has also started to include the positive side of the work-family interface by examining outcomes such as positive work-family spillover (Hanson et al., 2006), work-family enrichment (Greenhaus and Powell, 2006), or satisfaction with work-family balance (Valcour, 2007). However, the field has been criticised for its predominant use of samples from the United States and its focus on highly qualified professional and managerial workers. In an extensive review of work-family research methods, Casper et al. (2007) pointed out that 75 per cent of the empirical studies under review were based on a US sample, and that almost 70 per cent of the study participants were managerial and professional workers, whereas only six per cent of the respondents worked in lower-level occupations. Excluding non-managerial and non-professional employees, and disregarding different national and cultural settings in our empirical studies, may not only constrain the continued development of our field, but may also limit our ability to advise organizations and practitioners in different countries and cultures on how to create working environments which allow both professionals and non-professional employees to reconcile their work and non-work responsibilities in a satisfying manner.

The present study aims at addressing these gaps in work-family research by investigating differences in negative work-to-home interference (WHI) and satisfaction with work-family balance (SWFB) for professional and non-professional service sector employees in five Western European countries (Sweden, the United Kingdom, The Netherlands, Germany, and Portugal). These five countries represent four different welfare state regimes with varying levels of statutory workfamily policies (Esping-Andersen, 1999; Kovacheva et al., 2011) and different levels of national gender equality (UNDP, 2010). The different national contexts may influence the degree of work-family support and resources provided by organizations (den Dulk, 2005; Lyness and Kropf, 2005), and thus shape workers' opportunities to reconcile work and non-work responsibilities. More precisely, our study examines cross-national differences in the use of organizational work-family resources and their differential impact on WHI and SWFB of professional and non-professional service sector employees.

Empirical research and practical evidence suggest that working conditions of professional and non-professional employees differ significantly with respect to work demands and work resources (DiRenzo et al., 2011; Schieman et al., 
2006). Whereas work demands refer to workplace characteriztics that are associated with certain physiological and psychological costs, work resources are aspects of the work environment that increase goal achievement and personal health, and stimulate personal growth and development (Demerouti et al., 2001). Professional and non-professional employees may have different access to organizational resources, such as job autonomy and working-time flexibility (e.g. Fagan, 2003; Lawrence and Corwin, 2003), which in turn may differentially impact upon the ability of these occupational groups to achieve a satisfying level of work-family balance (e.g. Beham et al., 2012; Lambert and Haley-Lock, 2004). However, only a limited number of studies to date have explicitly examined the differential impact of work resources on the work-family interface of professional and non-professional workers or higher- versus lower-level employees (DiRenzo et al., 2011; Schieman et al., 2006). Both studies focused exclusively on work-family conflict and on national samples from the US and Canada, respectively. However, working conditions, work-family policies and opportunities for achieving work-family balance available to professionals and non-professionals may also differ across cross-national contexts. By extending the scope of the study to different national contexts, this research enhances our limited knowledge of cross-national variations in work-family outcomes among professional and non-professional workers. Further, we include SWFB as an additional outcome variable, and two types of organizational work-family resources (co-worker work-family support and the use of flexible working arrangements (FWA's)) as predictors. These variables have not been addressed in either of the studies mentioned above.

\section{Study Context}

The five Western European countries in our study represent different welfare state regimes with varying levels of state support for work-life integration (Esping-Andersen, 1999; Mills et al., 2014b; Kovacheva et al., 2011). The "social democratic" or "universalistic" regime of Sweden is characterized by extensive state work-life policies. Family wellbeing is conceived as a shared responsibility of the state or the municipality on the one hand and the family on the other. The Swedish state provides high levels of social security and encourages both men and women to enter into and remain in paid employment, while at the same time actively intervening to provide support services and meet the special needs of employed parents. In the "liberal" welfare state regime of the United Kingdom, the market is considered the main provider of support for the work-life balance of employees. State intervention is minimal and public childcare provision is at a low level (Mills et al., 2014a). The labor market is characterized by high flexibility of employment and low social protection of workers. Services 
that facilitate women's employment, such as care services, are mostly purchased in the market, with price determining their accessibility and quality. The "corporatist" or "conservative" regime of Germany and The Netherlands has long favored a male breadwinner model, which has recently evolved into a modified breadwinner model with one partner (usually the man) in full-time employment and the other partner caring for family members while working part-time. Public childcare provision (especially for very young children) is lower than in the social democratic regime. Both countries have a high degree of social protection, and part-time employment is exceptionally widespread in The Netherlands. Finally, the "Mediterranean" or "subprotective" welfare state regime of Portugal is characterized by relatively low state support for combining work and family life and a low degree of flexibility within the labor market. Despite some recent changes in state family policy (increased parental leave options and increased working time flexibility), the family continues to be the main care provider in Portugal. Actual take-up of these policies is low due to the economic necessity for full-time employment of both parents (Kovacheva et al., 2011).

The five European countries in our study not only differ in terms of statutory support for work-family balance but also with respect to national gender equality. National gender equality refers to the extent to which societies support women's development and achievements, and recognise the importance of including women in all aspects of life (UNDP, 2007). On a regular basis, the United Nations publishes the Gender Inequality Index (GII) which reflects gender inequality in reproductive health, empowerment, and the labor market. ${ }^{1}$ In our sample, The Netherlands and Sweden had the lowest GII in 2008, followed by Germany, Portugal, and the United Kingdom (UNDP, 2010). Another index assessing gender equality at a cross-national level, the Gender Gap Index (GGI) published by the World Economic Forum, provides a slightly different ranking. The GGI measures national gender gaps with economic, political, educational, and health-based criteria. In 2008, Sweden had the lowest overall gender gaps among our countries of interest, followed by The Netherlands, Germany, the United Kingdom, and Portugal (Hausmann et al., 2011). Work-family research suggests that the level of gender equality in a country influences employees' abilities to manage work and family, since gender equality in the workplace cannot be achieved without recognition and support of emp loyees' needs to reconcile work and non-work responsibilities (Lyness and Kropf, 2005; Poelmans and Sahibzada, 2004). Thus, we contend that understanding cross-country differences in approaching gender (in)equality is the key to understanding the role of the state, public policies, and cultural contexts of the work-family interface.

\footnotetext{
${ }^{1}$ The GII has replaced the former Gender Development Index (GDI). The available GII data for our five countries, that is closest to data collection in 2007, are from 2008.
} 


\section{Work-Family Outcomes}

Work-family conflict and the examination of its causes and consequences has long been the focal point of interest in work-family research. Research on work-family conflict distinguishes between two different directions of negative interference (work-to-family and family-to-work) and various types of conflict. Carlson et al. (2000), for example, distinguish between time-based, strain-based, and behavior-based work-to-family and family-to-work conflict. (Ezzedeen and Swiercz, 2007) identified cognitive work-family conflict as an additional form of work-non-work conflict. In this study, we focus on negative work-to-home interference which is the process in which an employee's functioning in the family domain is negatively influenced by load reactions (e.g. stress, strain) that have been built up in the work domain (Geurts et al., 2005).

More recently, work-family scholars have paid closer attention to other dependent variables, such as work-family enrichment and (satisfaction with) workfamily balance (Carlson et al., 2006, 2009; Valcour, 2007). Greenhaus and Powell (2006) define work-family enrichment 'as the extent to which experiences in one role improve the quality of life in the other role' (p. 73). Similar to workfamily conflict, work-family enrichment is a cross-domain construct describing the linking mechanism between the domains of work and family (Valcour, 2007), whereas work-family balance is a more global assessment of the extent to which an individual's effectiveness and satisfaction are compatible with individual life priorities (Greenhaus and Allen, 2011). Some scholars have criticized the concept of balance as a positive outcome, since it may assume that time and energy should be equally divided between the work and the family domain, and that all workers strive for the same thing (Kossek et al., 2015). We acknowledge that the meaning of balance may differ across individuals and that not all employees necessarily strive for the same level of balance. Nevertheless, recent research has identified work-family balance as a construct that is distinct from workfamily conflict and enrichment, and thus further research identifying its causes and consequences for individuals and organizations is warranted (Carlson et al., 2009; Drobnič et al., 2010; Drobnič and Guillén Rodríguez, 2011; Kalliath et al., 2012).

Following Carlson et al.'s (2009) suggestion to uncouple effectiveness and satisfaction in research on work-family balance, the present study focuses on satisfaction with work-family balance. SWFB refers to an individual's assessments of an adequate amount of resources to effectively respond to the demands of his/her work and family roles as well as to an individual's affective responses to this assessment (Valcour, 2007). 


\section{Organizational Work-Family Resources}

Empirical studies examining the antecedents of work-family conflict and SWFB mainly draw upon the job demands-resources model (Demerouti et al., 2001). According to this theoretical model, time-based demands (e.g. long working hours, overtime) and/or strain-based work demands (e.g. psychological pressure) constrain an employee's ability or willingness to meet the obligations of their family role, thereby leading to the experience of stress and strain (Frone et al., 1997). Research has consistently shown that these two major types of work demands are related to higher levels of WHI and lower levels of SWFB (e.g. Beham et al., 2010, 2011; Valcour, 2007; Voydanoff, 2005b,a).

Despite these negative aspects of modern working environments, workplaces may also offer various resources that can assist employees in better managing their work and non-work responsibilities. These work resources can be either intrinsic to the task (e.g. job variety, job autonomy) or located in the context of the workplace or broader work environment (e.g. social support at work) (Demerouti et al., 2001). Research has identified five major work resources that constitute a family-supportive work environment and specifically support employees to reconcile work and family life: a supportive work-family culture, a supportive supervisor, supportive co-workers, work-family policies, and job autonomy (Pitt-Catsouphes, 2002). Several empirical studies found these organizational work-family resources to be beneficial to employees with family responsibilities; they were found to be negatively related to WHI and positively related to SWFB (Allen, 2001; Beham et al., 2010, 2011; Major et al., 2008; Thomas and Ganster, 1995; Thompson et al., 1999; Valcour, 2007).

\section{Cross-National Variation in the Provision of Or- ganizational Work-Family Resources}

Organizations do not operate in a vacuum. The external social environment in which organizations are embedded may influence the provision of work-family support and resources at the organizational level (Poelmans and Sahibzada, 2004). According to institutional theory, organizations adapt their work-family practices in response to environmental pressure such as government regulations supporting the integration of work and family or cultural expectations (den Dulk, 2005; Lyness and Kropf, 2005). The different welfare state regimes in Europe represent different institutional contexts with varying levels of government regulation and statutory policies for work-non-work integration.

Whereas laws and government regulations may directly force organizations to implement work-family policies, they may also create public awareness and sensitivity of citizens towards work-family issues. Consequently, employees may 
develop a sense of entitlement (Lewis and Smithson, 2001) and expect the provision of organizational work-family resources as part of their employment relationship (den Dulk et al., 2012). Hence, in welfare state regimes with extensive statutory support for work-family balance (e.g. social democratic regimes such as Sweden or corporatist regimes such as The Netherlands), normative pressure on organizations to provide work-family support may emerge. In contrast, in an institutional context of low statutory work-family support, such as the liberal welfare state regime of the United Kingdom, organizations may gain an advantage over competitors by offering extensive organizational work-family support and resources that compensate for the lack of state-level policies (den Dulk, 2005; den Dulk et al., 2012; Poelmans and Sahibzada, 2004).

Further, in tight labor markets with a high demand for skilled workers, organizations providing extensive work-family resources may be better able to retain and attract highly qualified parents. Consequently, den Dulk et al. (2012) posit that employers are not only passively reacting to external pressure, but are also active agents who consciously make rational decisions about offering bundles of work-family resources that yield the highest net benefits.

Empirical studies provide support for this dual perspective. In support of institutional theory, organizations in social democratic welfare state regimes were found to provide the largest number of flexible working arrangements but did not supplement the extensive leave and childcare provisions offered by the state. In welfare state regimes with relatively few statutory work-family policies, such as the liberal regime in the United Kingdom, employers tend to offer a larger number and more different types of flexible work arrangements (Den Dulk, 2001; den Dulk, 2005). In the most recent study by den Dulk et al. (2012), however, employers in conservative welfare state regimes offered more flexible working arrangements than organizations in the liberal countries United Kingdom and Ireland. Employers in the Mediterranean regime offered the lowest number of FWA's.

In addition to the institutional context in different welfare state regimes, a country's degree of gender equality may also influence the provision of workfamily support at the organizational level (Poelmans and Sahibzada, 2004; Lyness and Kropf, 2005). Lyness and Kropf (2005) argue that the relationship between national gender equality and organizational focus on work-family issues can be explained in terms of both institutional theory and resource dependency theory.

According to institutional theory, organizations may respond to cultural expectations and regulations supporting gender equality, which should be higher in more gender egalitarian countries. Resource dependency theory suggests that organizations are more supportive of work-family issues when they greatly depend upon women, which is probably the case in more gender egalitarian 
countries (Dreher, 2003). Consequently, in countries with high levels of gender equality such as Sweden or The Netherlands, women are more likely to be valued members of the workforce, and organizations will be more supportive towards work-family issues than in countries with lower gender equality such as Portugal or the United Kingdom.

In their study among managers and professionals in 20 European countries, Lyness and Kropf (2005) indeed found positive relationships between national gender equality and perceived work-family culture and flexible working arrangements. In line with these findings and previous research on welfare state regimes, we expect organizations in countries with high gender equality and extensive statutory policies, such as Sweden, to provide the most extensive organizational work-family support, whereas in countries with lower gender equality and little statutory work-family support, such as the United Kingdom and Portugal, organizations will provide the lowest level of work-family support to their employees. For the two countries representing the conservative welfare state regime in our study, we expect The Netherlands to provide less organizational workfamily support than Sweden but higher levels than Germany. Although both countries are classified as conservative welfare state regimes by Esping-Andersen (1999), The Netherlands is often seen as an ambiguous case, as it also incorporates elements of the social democratic welfare state regime. In addition, the Dutch government more strongly encourages employers to provide work-family support (e.g. through tax deductions for childcare costs) than does Germany (den Dulk et al., 2012; van Oorschot, 2006). Consequently, it is hypothesized:

Hypothesis 1: Employees in Sweden and The Netherlands will report the highest levels of work-family resources in their organizations, whereas employees in the United Kingdom and Portugal will report the lowest levels of these resources. Workers in Germany will report fewer organizational work-family resources than employees in Sweden and The Netherlands but more organizational work-family resources than their peers in the United Kingdom and Portugal.

\section{Professional Work}

In recent years, a large body of research has been devoted to the work-family interface of professional workers due to the unique challenges and opportunities they face in balancing their work and non-work responsibilities. However, a widely accepted definition of professional status is still lacking. Whereas narrow definitions describe professionals in terms of the occupation they are working in (medical practitioners, lawyers, professors, etc.), broader definitions include advanced education and training, expertise and specialisation, high professional 
and organizational commitment, and high status in the organization as key features of professional work (Lawrence and Corwin, 2003; Reindl et al., 2011).

Research and practical evidence suggest that working conditions and work environments of professional and non-professional workers differ substantially. Usually, non-professional workers are more frequently found in low-level and low-wage service jobs with low job security, limited access to work-family policies, and often monotonous, routine work with little responsibility but also less ambiguity (Berg and Frost, 2005; Henly and Lambert, 2005; Lambert and Waxman, 2005; Weigt and Solomon, 2008). In contrast, professional work is usually characterized by higher occupational status and authority, good pay and career prospects. Professionals may experience less routine work and often substantial levels of autonomy which they acquire and sustain through their specific knowledge, training, and social status within organizations (Lawrence and Corwin, 2003). Because of these beneficial psychosocial and material conditions, professionals are often thought of as a privileged group in sociological research (Schieman et al., 2006). However, these advantages frequently come at the expense of long working hours (a frequent precondition for career advancement), high levels of availability and mobility, and work pressure (Reindl et al., 2011). Professional work is fluid and highly flexible (often in terms of both time and location) and thus prone to more frequent work-family role blurring (Lawrence and Corwin, 2003; Milliken and Dunn-Jensen, 2005; Schieman and Glavin, 2011). Research in the US and Europe provides empirical evidence that employees in higher-status occupations, such as professionals and managers, consistently experience higher levels of WHI than their peers in lower-status and non-professional occupations due to longer working hours and higher levels of job demands (DiRenzo et al., 2011; McGinnity and Calvert, 2009; Schieman et al., 2006).

\section{Professional Status as a Moderator of the Re- lationship Between Work-Family Resources and Work-Family Outcomes}

Higher-status professional and lower-status non-professional workers may not benefit from organizational work-family support and resources in the same way. Not only may professional and non-professional employees differ in opportunities to secure certain work resources (Lambert and Waxman, 2005), the positive effects of these resources on the work-family interface may also differ across occupational groups (DiRenzo et al., 2011). Job autonomy has been identified as a key feature of professional work. Professional workers acquire and sustain autonomy in their work through their expert knowledge, social acceptance of the profession's authority, and social status within the organization 
(Lawrence and Corwin, 2003). According to the job demands-resources framework (Demerouti et al., 2001), job autonomy may reduce the negative effects of job demands such as stress, strain, and WHI. Empirical results on the impact of job autonomy on work-family conflict are somewhat ambiguous. Whereas (Drobnič and Guillén Rodríguez, 2011) found job autonomy to be positively related to employees' WHI in Germany and Spain, other studies found control over one's work to be negatively related to employees' WHI and positively related to SWFB (Beham et al., 2010; Valcour, 2007). Since professional work is characterized by non-routine, non-standardized work and higher levels of stress, a high level of autonomy over one's work may be more beneficial to professional workers in reducing WHI and increasing SWFB than to non-professional employees whose work is often more standardized. DiRenzo et al. (2011) found job autonomy to reduce WHI of employees in higher-level jobs, such as managers and professionals, to a greater extent than in lower-level jobs. Consequently, it is hypothesized:

Hypothesis 2: The negative relationship between job autonomy and WHI (a) and the positive relationship between job autonomy and SWFB (b) will be stronger for professional workers than for non-professional workers.

Thompson et al. (1999) define work-family culture as 'the shared assumptions, beliefs, and values regarding the extent to which an organization supports and values the integration of employees' work and family lives' (p. 394). A family-supportive organizational culture was found to be negatively related to WHI because it reduces time demands and/or increases flexibility at work (Thompson et al., 1999). Further, Grandey et al. (2007) found the negative relationship between a family-supportive organizational culture and WHI to be stronger for employees who work long hours and experience higher levels of job demands. Since both of these factors apply more to professionals than to nonprofessional employees, a supportive organizational culture may more strongly decrease WHI (DiRenzo et al., 2011) and increase SWFB for professionals than for non-professional workers. Accordingly, it is hypothesized:

Hypothesis 3: The negative relationship between work-family culture and WHI (a) and the positive relationship between workfamily culture and SWFB (b) will be stronger for professional workers than for non-professional workers.

Empirical research has also identified supportive supervisors and co-workers as being important in reducing employees' WHI and increasing their SWFB (Abendroth and den Dulk, 2011; Dikkers et al., 2004; Hammer et al., 2011). Supervisor work-family support was found to be especially important for facilitating professional employees in meeting their work and family obligations 
(DiRenzo et al., 2011; Peper et al., 2011). Professional employees with high levels of job demands, time requirements, and mobility may need more flexibility and understanding from both their supervisor and co-workers than nonprofessional workers in routine jobs with lower work demands. Accordingly, it is hypothesized:

Hypothesis 4: The negative relationship between work-family supervisor support and WHI (a) and the positive relationship between work-family supervisor support and SWFB (b) will be stronger for professional workers than for non-professional workers.

Hypothesis 5: The negative relationship between work-family coworker support and WHI (a) and the positive relationship between work-family co-worker support and SWFB (b) will be stronger for professional workers than for non-professional workers.

Nowadays, a large number of organizations offer flexible working arrangements (e.g. flextime, compressed work weeks, telework) to assist their employees in managing work and family responsibilities, although the use of FWA's has not routinely been shown to help mitigate work-family conflict and increase workfamily balance in empirical research (e.g. Allen et al., 2013; Peper et al., 2011). Nevertheless, Peper et al. (2011) reported flexible working hours and telework to be very popular among professional workers since both policies greatly enhance their flexibility. Because of longer working hours and higher levels of job demands, FWA's may better assist professional workers in organizing their nonroutine and often stressful work than non-professional employees, whose work is often characterized by standardized routine procedures and lower levels of responsibility and stress (Präg and Mills, 2014). Accordingly, it is hypothesized:

Hypothesis 6: The negative relationship between FWA's and WHI (a) and the positive relationship between FWA's and SWFB (b) will be stronger for professional workers than for non-professional workers.

\section{Cross-National Differences Between Profession- als and Non-Professionals}

In the previous sections we have argued that the provision of organizational support varies across different welfare state regimes and levels of national gender equality, and that various work-family resources differentially impact the work-family interface of professional and non-professional workers. Research 
in the European context also suggests that the gap in work-family outcomes (WHI and SWFB) between professional and non-professional workers may vary across welfare state regimes. McGinnity and Calvert (2009) hypothesized that in countries with universal access to extensive statutory work-family support, such as Sweden and The Netherlands, the difference between professionals and non-professionals should be less pronounced than in countries with little or no governmental work-family support, such as the United Kingdom or Portugal. If professionals and non-professionals have equal access to these benefits, they may also experience comparable levels of WHI and SWFB. The gap between professionals and non-professionals should be moderate in countries with medium levels of state support such as Germany. McGinnity and Calvert (2009) found modest support for their hypotheses in a sample of eight European countries. The gap was smaller in Sweden than in the other countries (including Germany and the United Kingdom), but all the other countries did not differ significantly from each other. However, McGinnity and Calvert (2009) only accounted for work demands in their analyses. Since professionals and non-professionals may also differ in their access to work-family resources (see previous section on work resources), controlling for both work demands and work resources is essential when examining cross-national variation in occupational status differences. Accordingly, it is hypothesized:

Hypothesis 7: Differences in WHI (a) and SWFB (b) between professional and non-professional employees vary across countries. The gap between professionals and non-professionals will be less pronounced in Sweden and The Netherlands, moderate in Germany, and high in Portugal and the United Kingdom.

\section{Method}

\section{Sample and Procedure}

Respondents in this study were professional and non-professional service sector employees in Sweden, the United Kingdom, The Netherlands, Germany, and Portugal. Data were collected within a larger research project on quality of work and life funded by the European Commission (Bäck-Wiklund et al., 2011). In each country, employees working in four different service sector organizations (financial services, information and communication technology (ICT), health care, and retail) were surveyed. The companies were identified by the local research teams and invited to participate in the study via email or mail. The questionnaire was developed by the research team in English and was translated into the national languages of the participating countries using Brislin's (1986) back-translation method. Translations were made by bilingual researchers who 
were familiar with the local culture of each country. Pilot studies were conducted prior to data collection in each country to examine whether the questionnaires were appropriately translated into the national language. Only minor linguistic adaptations were necessary after the pilot study. Both online surveys and paper and pencil questionnaires were used to collect data in the five European countries. Response rates in the 20 organizations ranged from 20 per cent to 79 per cent. Further descriptions of the data can be found in Präg et al. (2011).

Table 1: Overview of Sample Composition, Percentages

\begin{tabular}{|c|c|c|c|c|c|c|}
\hline & Sweden & United Kingdom & The Netherlands & Germany & Portugal & Total \\
\hline Men & 41.9 & 42.5 & 33.1 & 54.8 & 47.0 & 44.3 \\
\hline Women & 58.1 & 57.5 & 66.9 & 45.2 & 53.0 & 55.7 \\
\hline Age (mean, range $21-66$ ) & 43.4 & 42.8 & 42.8 & 43.2 & 40.0 & 42.2 \\
\hline No. of children (mean, range $1-5$ ) & 1.8 & 1.8 & 1.9 & 1.6 & 1.5 & 1.7 \\
\hline \multicolumn{7}{|l|}{ Occupational status } \\
\hline Professionals & 69.5 & 52.5 & 59.1 & 74.6 & 65.5 & 64.8 \\
\hline Non-professionals & 30.5 & 47.5 & 40.9 & 25.4 & 34.5 & 35.2 \\
\hline \multicolumn{7}{|l|}{ Industry } \\
\hline Retail & 11.8 & 22.4 & 23.3 & 7.6 & 26.7 & 19.1 \\
\hline $\mathrm{ICT}$ & 36.2 & 30.5 & 18.4 & 52.6 & 21.8 & 31.0 \\
\hline Health care & 17.9 & 23.2 & 37.7 & 26.9 & 11.2 & 23.1 \\
\hline Finance & 34.1 & 23.9 & 20.6 & 13.0 & 40.3 & 26.8 \\
\hline$N$ & 246 & 259 & 408 & 409 & 528 & 1,850 \\
\hline
\end{tabular}

Table 1 gives an overview of the sample composition. We only included respondents who were married or cohabiting and living with at least one child in the household. Thus, our final sample consisted of 1,850 respondents with an average age of 42.2 years. Country samples varied between 246 study participants in Sweden and 528 employees in Portugal. Of our study participants, 55.7 per cent were female and 35.2 per cent were non-professional service workers. Women comprised 71.8 per cent of the non-professional and 46.9 per cent of the professional workers. Professionals worked on average 40.0 hours per week, whereas the actual average working hours for non-professional employees were 34.4 hours per week.

\section{Measures}

\section{Dependent Variables}

SWFB was measured with three items on a 5 -point Likert scale $(1=$ very dissatisfied to $5=$ very satisfied) developed by Valcour (2007). An example item is "How satisfied or dissatisfied are you with the way you divide your time between work and personal life?" $(\alpha=.91)$.

WHI was assessed with three items of the SWING Work-Home Interaction 
Survey Nijmegen (Geurts et al., 2005). An example item is "How often does it happen that you do not have the energy to engage in leisure activities with your spouse/family/friends because of your job?" $(\alpha=.75)$. Each item was rated on a 4 -point scale $(1=$ never; $4=$ always $)$.

Due to potential conceptual overlap between both dependent variables, a confirmatory factor analysis was conducted prior to hypothesis testing to verify that WHI and SWFB are different constructs. We tested a two-factor model versus a single-factor model. A Root Mean Square Error of Approximation (RMSEA) below .08 and a Comparative Fit Index (CFI) above .90 indicate good model fit. The results of this analysis show that the two-factor model $\left(\chi^{2}(9, N=1850)=40.46 ;\right.$ RMSEA $=.05 ;$ CFI $\left.=.99\right)$ fitted our data better than the single-factor model $\left(\chi^{2}(8, N=1850)=553.25\right.$; RMSEA $=.18 ; \mathrm{CFI}=$ $.90)$. The chi-square difference test $\left(\Delta \chi^{2}=512.79, \Delta d f=1\right)$ was significant at p i .01. Consequently, WHI and SWFB are distinct constructs.

\section{Independent Variables}

Job autonomy was assessed with two items taken from the decision authority scale of the Swedish Demand-Control-Support Questionnaire (DCSQ) (Sanne et al., 2005). Study participants responded to the following two items on a 4 -point scale $(1=$ never; $4=$ always): "Are you free to decide how your job is to be done?" and "Are you free to decide what your job involves?" $(\alpha=$ .74). Family-supportive organizational culture, family-supportive supervision, and work-family support from co-workers were each measured with three items on a 5 -point Likert scale ( $1=$ strongly disagree; $5=$ strongly agree) (Dikkers et al., 2004). Example items are, "In this organization, employees are expected to put their job before their private life when necessary" $(\alpha=.87)$, "My direct supervisor supports employees who want to switch to less demanding jobs for private reasons" ( $\alpha=.72)$, and "My colleagues support employees who want to reduce their working hours for private reasons" $(\alpha=.76)$, respectively. The use of flexible working arrangements was assessed by asking participants whether they had used flextime, telework or worked a compressed work week over the last twelve months. A sum score (values 0 to 3 ) was calculated, with 0 indicating that no flexible work arrangement had been used, and 3 indicating that all three flex-policies had been used over the last 12 months.

\section{Moderator}

Professional status was dummy-coded, with $1=$ professional and $0=$ nonprofessional. Survey participants provided the occupational title of their jobs. These descriptions were coded by national experts using the International Standard Classification of Occupations (ISCO-88). The Erikson and Goldthorpe (1992) scheme was used to assign participants to different occupational groups. 
This scheme, generally referred to as the EGP scheme, consists of 11 occupational groups allowing for comparative analyses between different employee categories. Following the approach advocated by McGinnity and Calvert (2009), the EGP classes "higher and lower professionals" were collapsed into a new category "professionals". The EGP classes "routine non-manual", "routine manual", "skilled manual", "semi-unskilled manual", and "manual supervisor" were classified as "non-professionals". We did not have the EGP classes "self-employed", "small employers", and "farm workers" in our sample. Both the ISCO-88 and the EGP scheme were developed for cross-national comparative research, and explicitly take the skill level of occupations, in terms of the amount of education required, into account (Ganzeboom and Treiman, 1996; Tåhlin, 2007). Professionals in our sample also reported significantly higher educational levels than non-professionals $(t(1,835)=-17.6, p<.01)$.

\section{Controls}

Since professional and non-professional jobs may differ significantly in psychological job demands and working hours, these variables are controlled for in the statistical analyses. Psychological job demands were measured with four items taken from the Swedish Demand-Control-Support Questionnaire (DCSQ) (Sanne et al., 2005). Participants responded on a 4 -point scale $(1=$ never; $4=$ always) to questions such as "Does your job require you to work very hard?" and "Do you have enough time to complete your job?" $(\alpha=.72)$. Working hours were measured as the average number of hours respondents devoted to their job in a typical week. Further, age, gender (dummy-coded with $1=$ female and $0=$ male), industry (dummy-coded with ICT as the reference category), and country (dummy-coded with the United Kingdom as the reference category) were included in all statistical models.

\section{Measurement Equivalence}

Since our data were collected in five different European countries, we conducted multi-group tests of measurement equivalence for all multi-item scales that had more than three items using AMOS 16.0 (Riordan and Vandenberg, 1994). Following the procedure outlined by Byrne (2004), we opted for a stringent test of measurement equivalence in which factor loadings, factor variances, and factor covariances were set equal across the five country samples. We conducted these tests for our measure of job demands (four items) and a combined measure of family-supportive organizational culture, family-supportive supervision, and family-supportive co-workers (nine items in total) because they had been taken from the same instrument. A good model fit would indicate that our measures are equivalent across all five country samples. Further, we conducted 
CFI difference tests as suggested by Cheung and Rensvold (2002). A $\Delta$ CFI of less than or equal to .01 would indicate measurement invariance across groups. The multi-group tests yielded adequate model fit for both measures. Several fit indices were within the usually accepted values of .90 for Comparative Fit Index (CFI) $(.94, .92)$, Normed Fit Index (NFI) $(.92, .90)$, and .08 for Root Mean Square Error of Approximation (RMSEA) $(.05, .04)$. In addition, a $\triangle$ CFI of .01 for both measures is indicative of measurement equivalence across the five country samples.

\section{Analytical Strategy}

Given the nested structure of our data (1,850 employees nested in 20 service organizations within five European countries), hierarchical linear (random coefficient) modeling (HLM) is recommended to test our study hypotheses (Raudenbush and Bryk, 2002). In a first step, we estimated baseline models without any predictors and calculated the intraclass correlation coefficient (ICC) for nestedness within organizations and within countries. For SWFB, two per cent of variance was located at the company level and five per cent at the country level. For WHI, two per cent of variation was found at the company level and three per cent at the country-level. For both variables, the bulk of variation (ca. $\tilde{9} 5 \%$ ) is thus located at the individual level. Nevertheless, Gelman and Hill (2007) also recommend using hierarchical linear modeling for low ICCs $(<.05)$, since HLM will yield more correct standard errors than ordinary least square regression. In HLM, very low numbers of higher-level units can lead to computational problems and might bias parameter estimates (Bell et al., 2014). The simulation study by Bell et al. (2014) suggests that ten units on the upper level can lead to biased parameter estimates, whereas 20 units yield correct estimates. Since we have only five countries at the upper level, calculating three-level models was not possible with our sample. Consequently, we estimated two-level models with employees at level 1 , organizations at level 2 , and country dummies included as level 2 covariates.

To enhance model estimation and the interpretation of the results, all independent variables were centered prior to analyses. Following the recommendations of Enders and Tofighi (2007), professional status, work demands, and work-family resources were group-mean centered, whereas socio-demographic variables, industry, and country dummies were grand-mean centered in all hierarchical linear models.

\section{Results}

Descriptive statistics and Pearson's correlation coefficients for the study variables (without country dummies) are presented in Table 2. 


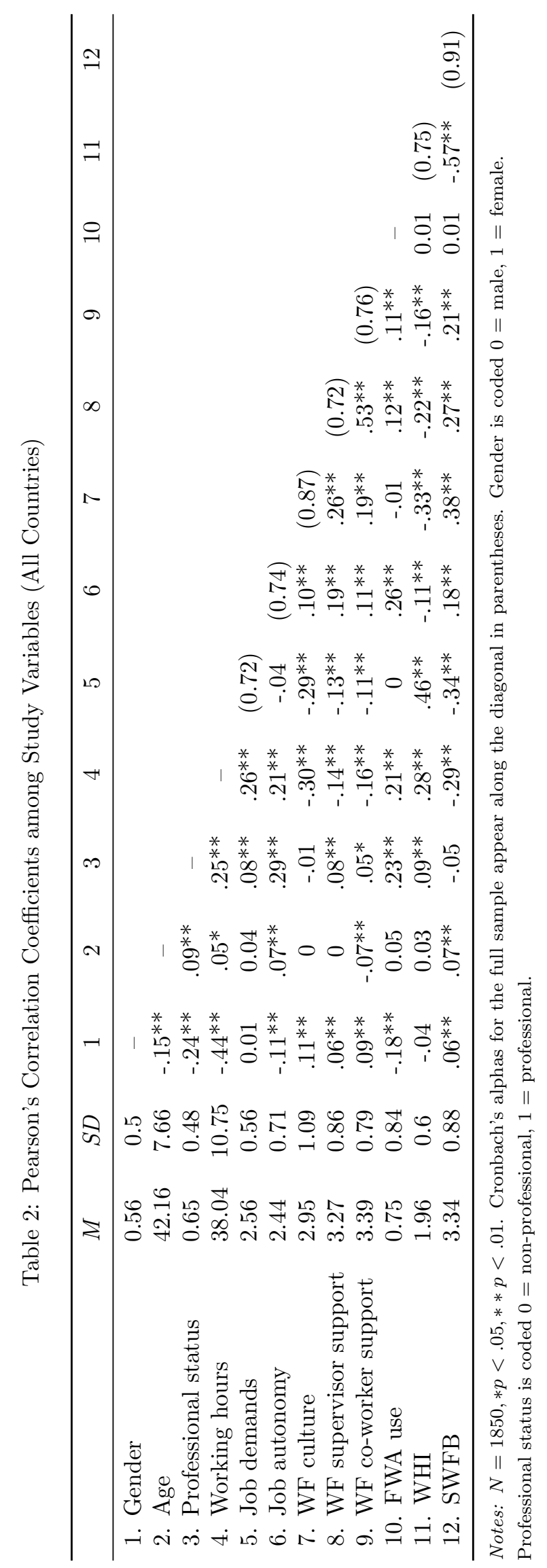


One important element of our analysis was testing cross-country differences in the use of organizational work-family supports. To compare the average level of work-family resources in various countries and to test Hypothesis 1, a series of one-way analysis of variance tests (ANOVA) were conducted, using the SPSS GLM univariate analysis of variance procedure. This procedure allowed us to control for several covariates, such as industry, professional status, age, and sex, and thus compare adjusted means across countries. The results of this analysis are reported in Table 3 .

Table 3: Comparison of Organizational Work-Family Resources (Adjusted Means) by Country

\begin{tabular}{|c|c|c|c|c|c|c|c|c|}
\hline Variables & Sweden & The Netherlands & United Kingdom & Germany & Portugal & Range & $F(d f)$ & $R^{2}$ \\
\hline Job autonomy & $2.68 \mathrm{a}$ & $2.38 \mathrm{~b}$ & $2.03 \mathrm{c}$ & $2.41 \mathrm{~b}$ & $2.60 \mathrm{a}$ & $1-4$ & $42.44(4,1849)$ & 0.162 \\
\hline WF culture & $3.23 \mathrm{~b}$ & $3.52 \mathrm{a}$ & $2.64 \mathrm{c}$ & $3.13 \mathrm{~b}$ & $2.39 \mathrm{~d}$ & $1-5$ & $86.72(4,1849)$ & 0.182 \\
\hline WF supervisor support & $3.60 \mathrm{a}$ & $3.51 \mathrm{a}$ & $3.17 \mathrm{~b}$ & $3.13 \mathrm{~b}$ & $3.11 \mathrm{~b}$ & $1-5$ & $26.43(4,1849)$ & 0.068 \\
\hline WF co-worker support & $3.70 \mathrm{a}$ & $3.72 \mathrm{a}$ & $3.36 \mathrm{~b}$ & $3.25 \mathrm{~b}$ & $3.11 \mathrm{c}$ & $1-5$ & $50.74(4,1849)$ & 0.115 \\
\hline FWA use & $1.21 \mathrm{a}$ & $0.61 \mathrm{c}$ & $0.88 \mathrm{~b}$ & $0.81 b$ & $0.54 \mathrm{c}$ & $0-3$ & $36.03(4,1849)$ & 0.139 \\
\hline
\end{tabular}

Notes: All $F$-tests are statistically significant at $p<.001$. Means with different superscripts are significantly different from one another after pairwise comparisons. Means are adjusted for the following covariates: professional status, sex, age, and industry.

The Swedish participants reported the most extensive use of FWA's in our sample and together with their Portuguese peers experienced significantly higher levels of job autonomy than service workers in the other three countries. Both Dutch and Swedish participants reported significantly higher levels of supervisor and co-worker work-family support than their peers in Germany, the United Kingdom, and Portugal. Interestingly, the Dutch together with the Portuguese service sector employees had the lowest levels of FWA use, but the Dutch also reported the most family-supportive organizational cultures (followed by Swedish and German participants) in our sample. British employees experienced the lowest levels of job autonomy, but the second highest use of FWA's. Together with the German study participants, they reported significantly lower levels of supervisor and co-worker support than the Swedish and Dutch service sector employees. The Portuguese service workers provided the lowest ratings for all work-family resources with the exception of job autonomy.

Although there is no clear-cut country ranking with respect to every single type of work-family resource, overall our results are in line with the hypothesized patterns that employees in Sweden and The Netherlands will report the highest levels of work-family resources, followed by German employees, and finally the British and Portuguese employees with generally lowest levels of work-family resources.

In the second part of our statistical analysis, the influence of work-family resources and professional status on WHI and SWFB is tested. Table 4 provides 
Table 4: Country Means of WHI and SWFB

\begin{tabular}{lcccccc}
\hline & Sweden & The Netherlands & United Kingdom & Germany & Portugal & Range \\
\hline WHI & 1.89 & 1.79 & 2.11 & 1.98 & 2.05 & $1-4$ \\
SWFB & 3.44 & 3.64 & 3.15 & 3.38 & 3.11 & $1-5$ \\
\hline
\end{tabular}

the country means for both dependent variables.

To test Hypotheses 2-7, hierarchical linear random intercept models with a stepwise integration of variables were estimated. Coefficients of fixed effects and corresponding standard errors, deviance, ICC, and variance components of the random intercept models are reported in Tables 5 and 6 . Table 5 presents the results for WHI. Model 1 includes professional status, country dummies, socio-demographic variables, and industry dummies. Professional status is significantly and positively related to WHI $(\beta=.17, p<.01)$, meaning that professionals experience significantly higher levels of negative work-to-home interference than non-professionals. The coefficient decreases in size and significance level $(\beta=.07, p<.05)$ when work demands are controlled for in Model 2, thereby indicating a partial mediation effect of job demands and working hours.

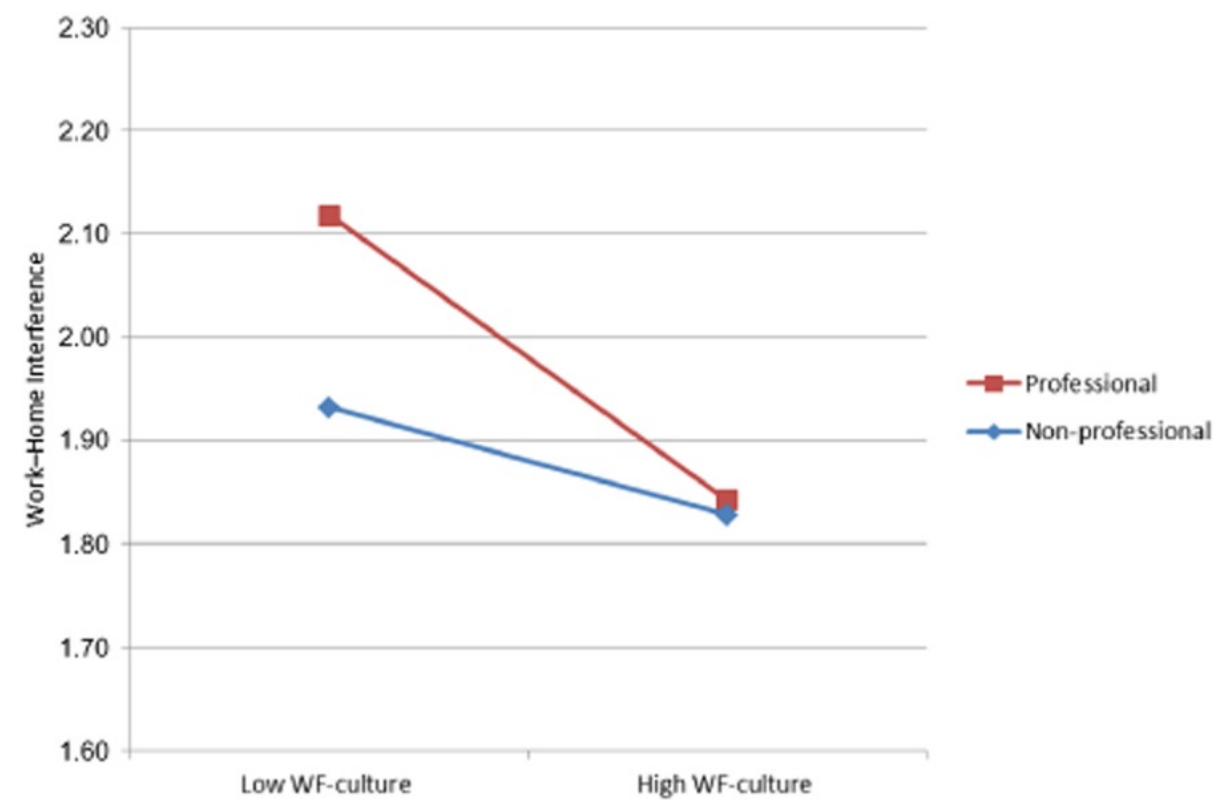

Figure 1: Interaction of professional status and work-family culture on WHI.

Adding work-family resources in Model 3 yielded significant and negative main effects for job autonomy, work-family culture and work-family supervisor support, whereas work-family co-worker support and the use of flexible working arrangements were not significantly related to WHI. Hypotheses $2 \mathrm{a}-6 \mathrm{a}$ 
Table 5: WHI Regressed on Work-Family Resources, HLM Modeling

\begin{tabular}{|c|c|c|c|c|c|c|c|c|c|c|}
\hline & $\beta$ & SE & $\beta$ & $\mathrm{SE}$ & $\beta$ & SE & $\beta$ & SE & $\beta$ & $\mathrm{SE}$ \\
\hline Professionals & $.17 * *$ & 0.03 & $.07^{*}$ & 0.03 & $.09^{* *}$ & 0.03 & $.10^{* *}$ & 0.03 & $.12^{* *}$ & 0.03 \\
\hline \multicolumn{11}{|l|}{ Country dummies } \\
\hline \multicolumn{11}{|l|}{ Ref.: United Kingdom } \\
\hline Sweden & $-.20 *$ & 0.08 & $-.20^{*}$ & 0.09 & $-.20 *$ & 0.09 & $-.21^{*}$ & 0.09 & $-.20^{*}$ & 0.09 \\
\hline The Netherlands & $-.31 * *$ & 0.08 & $-.31^{* *}$ & -0.09 & $-.31 * *$ & 0.09 & $-.32^{* *}$ & 0.09 & $-.32 * *$ & 0.08 \\
\hline Germany & -.12 & 0.08 & -.12 & 0.09 & -.12 & 0.09 & -.12 & 0.09 & -.12 & 0.09 \\
\hline Portugal & -.04 & 0.08 & -.05 & 0.09 & -.05 & 0.08 & -.05 & 0.08 & -.05 & 0.08 \\
\hline \multicolumn{11}{|l|}{ Control variables } \\
\hline Female & 0.01 & 0.03 & $.07 * *$ & 0.03 & $.07 * *$ & 0.03 & $.08^{* *}$ & 0.03 & $.07 * *$ & 0.03 \\
\hline Age & .00 & 0.00 & .00 & 0.00 & .00 & 0.00 & .00 & 0.00 & .00 & 0.00 \\
\hline \multicolumn{11}{|l|}{ Industry dummies } \\
\hline \multicolumn{11}{|l|}{ Ref.: ICT } \\
\hline Finance & -.09 & 0.07 & -.09 & 0.08 & -.09 & 0.08 & -.10 & 0.07 & -.10 & 0.07 \\
\hline Health care & .00 & 0.07 & -.02 & 0.08 & -.02 & 0.08 & -.02 & 0.08 & -.02 & 0.08 \\
\hline Retail & 0.06 & 0.07 & 0.04 & 0.08 & 0.04 & 0.08 & 0.04 & 0.08 & 0.04 & 0.08 \\
\hline \multicolumn{11}{|l|}{ Work demands } \\
\hline Actual working hours & & & $.01^{* *}$ & 0.00 & $.01^{* *}$ & 0.00 & $.01^{* *}$ & 0.00 & $.01^{* *}$ & 0.00 \\
\hline Job demands & & & $.44^{* *}$ & 0.02 & $.38^{* *}$ & 0.02 & $.38^{* *}$ & 0.02 & $.38^{* *}$ & 0.02 \\
\hline \multicolumn{11}{|l|}{ Work-family resources } \\
\hline Job autonomy & & & & & $-.06 * *$ & -0.02 & $-.06^{* *}$ & -0.02 & $-.06^{* *}$ & -0.02 \\
\hline WF culture & & & & & $-.10^{* *}$ & -0.01 & $-.10^{* *}$ & -0.01 & $-.10^{* *}$ & -0.01 \\
\hline WF supervisor support & & & & & $-.05^{* *}$ & -0.02 & $-.05^{* *}$ & -0.02 & $-.05^{* *}$ & -0.02 \\
\hline WF co-worker support & & & & & -.02 & -0.02 & -.01 & -0.02 & -.01 & -0.02 \\
\hline FWA use & & & & & 0.01 & -0.02 & 0 & -0.02 & 0 & -0.02 \\
\hline \multicolumn{11}{|l|}{ Interactions } \\
\hline Professional $\times$ job autonomy & & & & & & & 0 & -0.05 & -.01 & -0.05 \\
\hline Professional $\times$ WF culture & & & & & & & $-.09^{* *}$ & -0.03 & $-.09^{* *}$ & -0.03 \\
\hline Professional $\times$ WF supervisor support & & & & & & $.09^{*}$ & -0.04 & $.10^{*}$ & -0.04 & \\
\hline Professional $\times$ WF co-worker support & & & & & & -.05 & -0.04 & -.05 & -0.04 & \\
\hline Professional $\times$ FWA use & & & & & & & 0.07 & -0.04 & 0.07 & -0.04 \\
\hline \multicolumn{11}{|l|}{ County interactions } \\
\hline \multicolumn{11}{|l|}{ Ref.: Prof $\times$ UK } \\
\hline Professional $\times$ Sweden & & & & & & & & & -.17 & -0.13 \\
\hline Professional $\times$ Netherlands & & & & & & & & & $-.37^{* *}$ & -0.11 \\
\hline Professional $\times$ Germany & & & & & & & & & $-.39^{* *}$ & -0.12 \\
\hline Professional $\times$ Portugal & & & & & & & & & $-.30^{* *}$ & -0.11 \\
\hline Intercept & $1.97^{* *}$ & & $1.93^{* *}$ & & $1.93^{* *}$ & & $1.92^{* *}$ & & $1.92^{* *}$ & \\
\hline Var(intercept) & 0.01 & & 0.01 & & 0.01 & & 0.01 & & 0.01 & \\
\hline Var(residual) & 0.34 & & 0.27 & & 0.25 & & 0.25 & & 0.25 & \\
\hline $\mathrm{ICC}$ & 0.03 & & 0.04 & & 0.04 & & 0.04 & & 0.04 & \\
\hline Deviance & $3,329.64$ & & $2,903.14$ & & $2,830.11$ & & $2,839.12$ & & $2,837.31$ & \\
\hline
\end{tabular}

Notes: $* p<.05, * * p<.01$. 


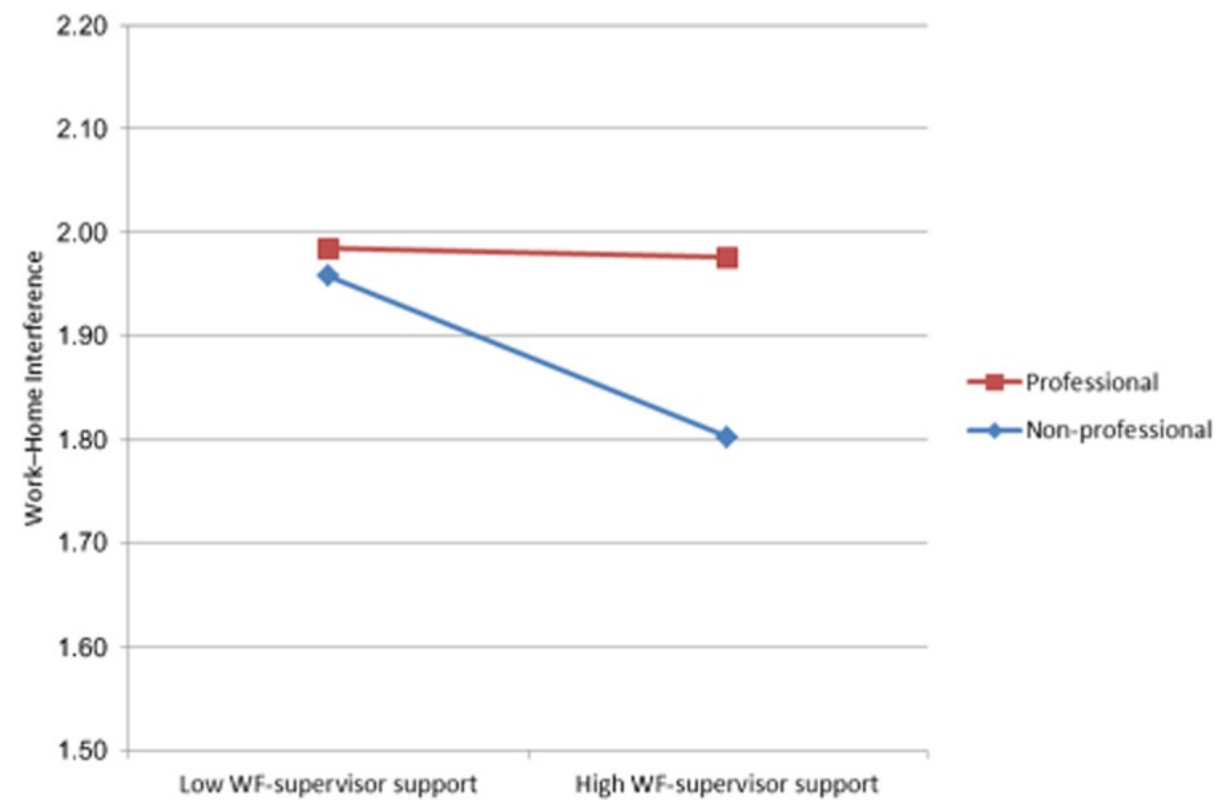

Figure 2: Interaction of professional status and work-family supervisor support on WHI.

suggested that professionals will benefit more from organizational work-family resources than non-professionals. In Model 4, interaction terms for all workfamily resources were included. However, only the interactions of professional status with family-supportive organizational culture $(\beta=-.09, p<.01)$ and supervisor work-family support $(\beta=.09, p<.05)$ were found to be significant. We plotted the significant interactions to illustrate the shape of the moderating effects. Figure 1 shows that, in line with predictions, a family-supportive organizational culture seems to decrease WHI to a larger extent for professional employees than for non-professional workers. However, Figure 2 depicts an unexpected effect for work-family supervisor support, suggesting that a supportive supervisor mitigates WHI to a larger extent for non-professional workers than for professionals. To summarise, our data only provide support for Hypothesis $3 \mathrm{a}$.

To test Hypothesis 7a, interaction terms (professional status $\times$ country) were included in Model 5. The negative interaction terms for The Netherlands, Germany, and Portugal indicate that the difference in WHI between professionals and non-professionals in these countries is smaller than in the United Kingdom and Sweden above and beyond work demands and resources. The gap between professionals and non-professionals is particularly pronounced in the United Kingdom, but it is also high in Sweden, which was not expected. Consequently, Hypothesis 7a received partial support.

Country dummies were included in all models in Table 5. Our analysis with 
the United Kingdom as the reference category reveals no statistically significant differences between British, Portuguese, and German employees. However, significant negative coefficients for Sweden and The Netherlands suggest that in these countries WHI is considerably lower than in the other countries.

Table 6: SWFB Regressed on Work-Family Resources, HLM Modeling

\begin{tabular}{|c|c|c|c|c|c|c|c|c|c|c|}
\hline & \multicolumn{2}{|c|}{ Model 1} & \multicolumn{2}{|c|}{ Model 2} & \multicolumn{2}{|c|}{ Model 3} & \multicolumn{2}{|c|}{ Model 4} & \multicolumn{2}{|c|}{ Model 5} \\
\hline & $\beta$ & $\mathrm{SE}$ & $\beta$ & $\mathrm{SE}$ & $\beta$ & $\mathrm{SE}$ & $\beta$ & $\mathrm{SE}$ & $\beta$ & $\mathrm{SE}$ \\
\hline Professionals & $-.17^{* *}$ & $(0.05)$ & -.06 & $(0.05)$ & $-.13^{* *}$ & $(0.04)$ & $-.13^{* *}$ & $(0.04)$ & $-.14^{* *}$ & $(0.05)$ \\
\hline \multicolumn{11}{|l|}{ Country dummies } \\
\hline \multicolumn{11}{|l|}{ Ref.: United Kingdom } \\
\hline Sweden & $.28^{* *}$ & $(0.09)$ & $.28^{* *}$ & $(0.10)$ & $.28^{* *}$ & $(0.10)$ & $.28^{* *}$ & $(0.10)$ & $.28^{* *}$ & $(0.10)$ \\
\hline The Netherlands & $.44^{* *}$ & $(0.09)$ & $.45^{* *}$ & $(0.09)$ & $.45^{* *}$ & $(0.09)$ & $.45^{* *}$ & $(0.09)$ & $.45^{* *}$ & $(0.09)$ \\
\hline Germany & $.25^{*}$ & $(0.08)$ & $.26^{*}$ & $(0.09)$ & $.26^{*}$ & $(0.09)$ & $.26^{*}$ & $(0.09)$ & $.26^{*}$ & $(0.09)$ \\
\hline Portugal & -.02 & $(0.08)$ & -.02 & $(0.09)$ & -.02 & $(0.09)$ & -.01 & $(0.09)$ & -.01 & $(0.09)$ \\
\hline \multicolumn{11}{|l|}{ Control variables } \\
\hline Female & 0.02 & $(0.04)$ & -.07 & $(0.04)$ & -.07 & $(0.04)$ & -.07 & $(0.04)$ & -.07 & $(0.04)$ \\
\hline Age & 0.00 & $(0.00)$ & $.01^{* *}$ & $(0.08)$ & $.01^{* *}$ & $(0.00)$ & $.01^{* *}$ & 0.00 & $.01^{* *}$ & $(0.00)$ \\
\hline \multicolumn{11}{|l|}{ Industry dummies } \\
\hline \multicolumn{11}{|l|}{ Ref.: ICT } \\
\hline Finance & 0.08 & $(0.07)$ & 0.09 & $(0.08)$ & 0.09 & $(0.08)$ & 0.1 & $(0.08)$ & 0.1 & $(0.08)$ \\
\hline Health care & $.21^{*}$ & $(0.07)$ & $.24^{*}$ & $(0.08)$ & $.24^{*}$ & $(0.08)$ & $.24^{*}$ & $(0.08)$ & $.24^{*}$ & $(0.08)$ \\
\hline Retail & 0.08 & $(0.08)$ & 0.11 & $(0.09)$ & 0.11 & $(0.08)$ & 0.11 & $(0.08)$ & 0.11 & $(0.08)$ \\
\hline \multicolumn{11}{|l|}{ Work demands } \\
\hline Actual working hours & & & $-.02^{* *}$ & 0.00 & $-.02^{* *}$ & 0.00 & $-.02^{* *}$ & 0.00 & $-.02^{* *}$ & 0.00 \\
\hline Job demands & & & $-.46^{* *}$ & $(0.04)$ & $-.32^{* *}$ & $(0.04)$ & $-.32^{* *}$ & $(0.04)$ & $-.32^{* *}$ & $(0.04)$ \\
\hline \multicolumn{11}{|l|}{ Work-family resources } \\
\hline Job autonomy & & & & & $.21^{* *}$ & $(0.03)$ & $.21^{* *}$ & $(0.03)$ & $.21^{* *}$ & $(0.03)$ \\
\hline WF culture & & & & & $.18^{* *}$ & $(0.02)$ & $.18^{* *}$ & $(0.02)$ & $.18^{* *}$ & $(0.02)$ \\
\hline WF supervisor support & & & & & $.12^{* *}$ & $(0.02)$ & $.12^{* *}$ & $(0.02)$ & $.12^{* *}$ & $(0.02)$ \\
\hline WF co-worker support & & & & & $.06^{*}$ & $(0.03)$ & $.06^{*}$ & $(0.03)$ & $.06^{*}$ & $(0.03)$ \\
\hline FWA use & & & & & 0 & $(0.03)$ & 0 & $(0.03)$ & 0 & $(0.03)$ \\
\hline \multicolumn{11}{|l|}{ Interactions } \\
\hline Professional $\times$ job autonomy & & & & & & & 0.06 & $(0.07)$ & 0.06 & $(0.07)$ \\
\hline Professional $\times$ WF culture & & & & & & & 0.1 & $(0.05)$ & 0.08 & $(0.05)$ \\
\hline Professional $\times$ WF supervisor support & & & & & & -.09 & -0.06 & -.10 & -0.06 & \\
\hline Professional $\times$ WF co-worker support & & & & & & -.02 & -0.06 & -.02 & -0.06 & \\
\hline Professional $\times$ FWA use & & & & & & & -.09 & $(0.06)$ & -.09 & $(0.06)$ \\
\hline \multicolumn{11}{|l|}{ County interactions } \\
\hline \multicolumn{11}{|l|}{ Ref.: Prof $\times$ UK } \\
\hline Professional $\times$ Sweden & & & & & & & & & 0.02 & $(0.20)$ \\
\hline Professional $\times$ Netherlands & & & & & & & & & 0.06 & $(0.17)$ \\
\hline Professional $\times$ Germany & & & & & & & & & 0.26 & $(0.17)$ \\
\hline Professional $\times$ Portugal & & & & & & & & & 0.04 & $(0.18)$ \\
\hline Intercept & $3.32^{* *}$ & & $3.37^{* *}$ & & $3.37^{* *}$ & & $3.38^{* *}$ & & $3.38^{* *}$ & \\
\hline Var (intercept) & 0.01 & & 0.01 & & 0.01 & & 0.01 & & 0.01 & \\
\hline Var (residual) & 0.72 & & 0.63 & & 0.57 & & 0.56 & & 0.56 & \\
\hline ICC & 0.01 & & 0.02 & & 0.02 & & 0.02 & & 0.02 & \\
\hline Deviance & $4,686.42$ & & $4,463.46$ & & $4,256.75$ & & $4,267.88$ & & $4,272.79$ & \\
\hline
\end{tabular}

Notes: $* p<.05, * * p<.01$.

Table 6 presents the results for SWFB. Model 1 shows a significant, negative relationship between professional status and SWFB $(\beta=-.17, p<.01)$. The regression coefficient for professional status became non-significant when working hours and job demands were included in the equation (Model 2), suggesting a mediation effect of work demands. However, the main effect of professional status becomes statistically significant again when work resources are controlled for in Models 3 and 4.

According to Hypotheses $2 \mathrm{~b}-6 \mathrm{~b}$, work-family resources should increase SWFB more strongly for professional workers. Adding work-family resources in Model 3 
yielded significant and positive main effects for all types of resources except for the use of FWA's. However, our moderator analysis yielded no significant interaction effect (Model 4). Consequently, Hypotheses 2b-6b were not supported.

No significant interaction terms for professional status and country were found in Model 5. Thus, Hypothesis 7b was not supported. The significant country dummies for Sweden, The Netherlands, and Germany in all models indicate that the Swedish, Dutch, and German participants were generally more satisfied with their work-family balance than their peers in the United Kingdom and Portugal.

\section{Discussion}

The purpose of our study was twofold: To examine cross-national differences in the provision and use of organizational work-family resources and to investigate the differential impact of these resources on the work-family interface of professional and non-professional service sector employees in five Western European countries. In line with our predictions, statistical analyses revealed significant cross-nation variation in the use of organizational work-family resources across the five countries. Different welfare state regimes and national gender equality in these countries may account for these differences in organizational level support for work-family integration. Further, our results provide only partial support for the differential impact of organizational work-family resources on WHI of professional and non-professional services workers. We did not find such an effect for SWFB. Overall, professionals were found to experience significantly higher levels of WHI and lower levels of SWFB than their non-professional peers. Cross-national analyses further revealed a significantly larger gap between professionals and non-professional service sector workers with respect to WHI (but not SWFB) in The Netherlands, Germany, and Portugal than in the United Kingdom and in Sweden. These findings are discussed in more detail in the following sections.

\section{Cross-National Differences in the Use of Work-Family Re- sources}

We started with an examination of the link between national context and workfamily support at the organizational level. The five countries in our study not only differed with respect to governmental work-family support and national gender equality but also in terms of work-family resources at the organizational level as reported by the study participants. Drawing upon institutional theory, rational choice, and resource dependency theory, previous research suggested that both aspects of the national context may influence the provision of work- 
family support at the organizational level (Den Dulk, 2001; den Dulk, 2005; den Dulk et al., 2012; Lyness and Kropf, 2005; Poelmans and Sahibzada, 2004). Although we do not find the same patterns of results for all five types of workfamily resources, our findings in general seem to support our argument that in countries with extensive governmental support and high gender equality, organizations also provide more work resources that support employees in meeting their non-work responsibilities. In less gender egalitarian countries with less state support, the provision of work-family support at the organizational level also seems to be low. The Swedish participants in our study, who live in a highly egalitarian society with extensive statutory policies, reported the highest levels of job autonomy, flex policy use, and work-family support from colleagues and supervisors. Dutch employees experienced comparable levels of co-worker and supervisor support to their Swedish peers and reported the most supportive organizational cultures. Both countries rank high on gender equality and have medium to high levels of statutory work-family policies, thereby lending additional support to the institutional argument that extensive levels of public work-family support can create a normative climate that increases employers' and individuals' sensitivity to work-family issues (den Dulk et al., 2012). Interestingly though, the Dutch employees, together with the Portuguese participants, reported the least extensive use of flextime, compressed work weeks, and telework. This may be due to the high popularity and extensive use of part-time work in The Netherlands, which may to some extent supersede other FWA's. Part-time work was not included in our measure of FWA use.

In line with our reasoning on the institutional context and national gender equality, the Portuguese participants reported the lowest levels for all workfamily resources, with the exception of job autonomy. The lowest levels of job autonomy were reported by British study participants, but they reported comparable levels of work-family co-worker and supervisor support to their peers in Germany. Also similar to the German participants, the British employees reported the second highest use of FWA's in our sample, thereby confirming that organizations in the liberal welfare state regime may to some extent compensate for the lack of governmental work-family support through the provision of a broad range of flexible working arrangements (Den Dulk, 2001; den Dulk, 2005; den Dulk et al., 2012).

\section{Links between Organizational Work-Family Resources and Work-Family Outcomes}

Our analysis of the differential impact of work-family resources on work-family outcomes for professional and non-professional workers in European service sector organizations yielded somewhat different results from hypothesized and reported in US-based research. Job autonomy, work-family culture, and work- 
family supervisor support significantly decreased WHI when controlling for work demands in our analysis. However, whereas DiRenzo et al. (2011) reported significant interaction effects for all three types of resources and professional status, our study only yielded significant interaction effects for supervisor support and work-family culture. Job autonomy seems to be as beneficial to WHI and SWFB of professional as to non-professional workers. Work-family support from coworkers seems to be equally important for professionals' and non-professionals' SWFB, but does not seem to be beneficial in mitigating WHI for either group. Interestingly, the use of flexible working arrangements, such as flextime, compressed work week, or telework neither seems to decrease WHI nor increase SWFB for employees in our study. Neither our overall measure nor a separate inclusion of the different types of FWA's into our models yielded significant relationships (analysis not shown; available upon request). We suggest two explanations for these findings. Our measure of FWA use is somewhat crude and does not measure degree or frequency of use. Future research may want to include more precise measures of FWA use. Further, the types of FWA's included in our study may not always be beneficial to employees. Rather, these FWA's may allow employees to work even more hours than without opportunities for flexibility (Dikkers et al., 2010).

A family-supportive organizational culture seems to be more beneficial to professional than to non-professional workers in mitigating WHI. On the other hand, a supportive supervisor seems to have a stronger effect on WHI for nonprofessional workers than for their peers in professional jobs. One explanation could be that professional workers are often supervisors themselves who are in a position to create a family-supportive work environment. Since non-professional employees may have less agency in crafting a family-supportive work environment than professional employees, they may depend more heavily on the assistance of their direct supervisor when it comes to reconciling their work and non-work responsibilities.

Our findings on work-family resources are above and beyond work demands. Actual working hours and psychological job demands were included as control variables in statistical analyses. According to the 'stress of higher status hypothesis' in sociological research (Schieman et al., 2006), professional workers, though privileged in terms of specific working conditions such as pay, prestige, career advancement, and autonomy, are at a disadvantage when it comes to reconciling work and non-work responsibilities and achieving a satisfying level of work-family balance because of long working hours and high levels of job demands. In line with previous empirical research in the US, Canada, and Western European countries (DiRenzo et al., 2011; McGinnity and Calvert, 2009; Schieman et al., 2006; Tausig and Fenwick, 2001), the professional service sector employees in our sample also experienced higher levels of work-to-home conflict 
and lower levels of SWFB than their non-professional peers. A combination of higher levels of psychological job demands and longer working hours seems to at least partially account for these differences in work-family outcomes between professional and non-professional workers, as indicated by (partial) mediation effects of work demands in Model 2, Tables 4 and 5.

\section{Cross-National Differences in Work-Family Outcomes}

Further, our study also yielded some important cross-national differences with respect to both work-family outcomes. Our statistical models show that service sector workers in Sweden, The Netherlands, and Germany were more satisfied with their work-family balance than their peers in the United Kingdom and Portugal. These differences may be attributed to variations in state-level support in the different welfare state regimes, with the liberal regime in the United Kingdom and the Mediterranean regime in Portugal providing considerably lower levels of statutory policies for work-life integration than the social democratic and conservative regimes in the other three countries (Kovacheva et al., 2011). Further, it becomes evident that employees (both professionals and non-professionals) in The Netherlands experience the lowest levels of WHI and are most satisfied with their work-family balance above and beyond work demands and resources. This finding may be attributed to the widespread use of part-time work in this country. The Netherlands has been termed the first part-time economy in the world, with a highly regulated and protected labor market (Visser, 2002). The "normalisation" of part-time employment and its rapid diffusion drew attention to other issues and social policy concerns, most prominently the issue of how to combine work and care (Visser, 2002). It seems that these developments have had a broad societal impact that goes beyond the effects of an individual's work hours which is controlled in our analysis.

Service sector employees in the United Kingdom experienced the highest levels of WHI in our sample, closely followed by Portuguese and German employees. In the United Kingdom and Portugal, the provision of statutory work-family support is considerably lower than in the other three countries, which may explain the comparably high levels of WHI experienced by respondents in these countries above and beyond work demands and work-family resources at the organizational level. Germany, a country with a medium level of state support for work-family integration, was indeed found to be in the middle position in this cross-country comparison in terms of WHI, but it did not differ significantly from the United Kingdom and Portugal. However, German respondents were more satisfied with their work-family balance and in this respect joined The Netherlands and Sweden. Germany provides on average more governmental work-family support than the United Kingdom or Portugal, but compared to Sweden it lacks statutory childcare support for children under the age of 3 or 
the extensive use of part-time working arrangements as in The Netherlands.

Finally, we were also interested in whether the gap between professional and non-professional service workers with respect to work-family outcomes differed across countries. Our analysis yielded some country variation for WHI, which is in line with previous research in a European context (McGinnity and Calvert, 2009), but we did not find any variation across countries for SWFB. As expected, the difference between professionals and non-professionals was larger in the United Kingdom than in any other country. The gap in WHI was significantly smaller in Germany and The Netherlands, both countries with a medium to high level of state support. However, the difference between professionals and non-professionals was also significantly smaller in Portugal, a country with low statutory provision of work-family support but extensive informal family networks which may compensate for the lack of governmental support. Contrary to the findings of McGinnity and Calvert (2009), in Sweden, a very egalitarian country with universal access to extensive governmental work-family support, the difference between professional and non-professional employees was significantly higher than in Germany, The Netherlands, and Portugal when work demands and work-family resources were taken into account. A possible explanation for the differing results may be the different samples and the inclusion of organizational work-family resources in our study. Whereas the representative country sample used by McGinnity and Calvert (2009) comprised employees from different industries, our non-representative sample only included professionals and non-professionals working in certain service sector organizations whose occupational context may be different from those of other industries.

\section{Limitations and Future Research Suggestions}

Cross-sectional data used in the analysis call for caution in interpreting causal relationships between the variables, since rival explanations for significant relationships cannot be ruled out. In addition, all variables were self-reported by the study participants, introducing the possibility that common method bias may influence the study results (Spector, 2002; Stone-Romero and Rosopa, 2007). Since our sample comprised service sector employees in four different industries, the results of our study may not generalise to a larger population of workers. In addition, our nested data structure, the small number of countries, and the lack of cultural values assessed in this study restricted our ability to perform cross-national comparative research. Future studies would definitely benefit from longitudinal designs and samples including a broader array of industries and a larger number of culturally and economically diverse countries. Nevertheless, our study provides additional insights into cross-national differences in the use of organizational work-family resources and the relationships between these resources and the work-family interface of professional and non-professional 
service sector workers in Western Europe.

\section{References}

Abendroth, Anja-Kristin and Laura den Dulk, 2011. 'Support for the Work-Life Balance in Europe. The Impact of State, Workplace, and Family Support on Work-Life Balance Satisfaction.' Work, Employment, and Society 25(2): 234-256. doi: 10.1177/0950017011398892.

Allen, Tammy D., 2001. 'Family-Supportive Work Environments. The Role of Organizational Perceptions.' Journal of Vocational Behavior 58(3): 414-435. doi: $10.1006 /$ jvbe.2000.1774.

Allen, Tammy D., Ryan C. Johnson, Kaitlin M. Kiburz, and Kristen M. Shockley, 2013. 'Work-Family Conflict and Flexible Work Arrangements. Deconstructing Flexibility.' Personnel Psychology 66(2): 345-376. doi: 10.1111/peps.12012.

Bäck-Wiklund, Margareta, Tanja van der Lippe, Laura den Dulk, and Anneke van Doorne-Huiskes, 2011. Quality of Life and Work in Europe. Theory, Practice, and Policy. Houndmills, Basingstoke: Palgrave Macmillan. doi: 10.1057/9780230299443.

Beham, Barbara, Sonja Drobnič, and Patrick Präg, 2011. 'Work Demands and Resources and the Work-Family Interface. Testing a Salience Model on German Service Sector Employees.' Journal of Vocational Behavior 78(1): 110-122. doi: $10.1016 /$ j.jvb.2010.07.008.

Beham, Barbara, Patrick Präg, and Sonja Drobnič, 2010. 'Balance zwischen Erwerbstätigkeit und Familienleben. Eine vergleichende Studie unter Eltern in vier europäischen Ländern.' In Schmidt, Matthias and Christoph Schank, eds., Die Metropolregion Berlin vor demografischen und gesellschaftlichen Herausforderungen, pp. 81-104. Munich: Hampp. doi: 10.31235/osf.io/vq4ek.

- 2012. 'Who's Got the Balance? A Study of Satisfaction with the Work-Family Balance among Part-Time Service Sector Employees in Five Western European Countries.' International Journal of Human Resource Management 23(18): 3725-3741. doi: 10.1080/09585192.2012.654808.

Bell, Bethany A., Grant B. Morgan, Jason A. Schoeneberger, Jeffrey D. Kromrey, and John M. Ferron, 2014. 'How Low Can You Go? An Investigation of the Influence of Sample Size and Model Complexity on Point and Interval Estimates in Two-Level Linear Models.' Methodology 10(1): 1-11. doi: 10.1027/1614-2241/a000062. 
Berg, Peter and Ann Frost, 2005. 'Dignity at Work for Low-Wage, Low-Skill Service Workers.' Relations industrielles 60(4): 657-682. doi: 10.7202/012339ar.

Brislin, Richard W., 1986. 'The Wording and Translation of Research Instruments.' In Berry, John W. and Walter J. Lonner, eds., Field Methods in Cross-Cultural Research, pp. 137-164. Beverly Hills, CA: Sage.

Byrne, Barbara M., 2004. 'Testing for Multigroup Invariance Using AMOS Graphics. A Road Less Traveled.' Structural Equation Modeling. A Multidisciplinary Journal 11(2): 272-300. doi: 10.1207/s15328007sem1102_8.

Carlson, Dawn S., Joseph G. Grzywacz, and Suzanne Zivnuska, 2009. 'Is Work-Family Balance More than Conflict and Enrichment?' Human Relations 62(10): 1459-1486. doi: 10.1177/0018726709336500.

Carlson, Dawn S., K. Michele Kacmar, Julie Holliday Wayne, and Joseph G. Grzywacz, 2006. 'Measuring the Positive Side of the Work-Family Interface. Development and Validation of a Work-Family Enrichment Scale.' Journal of Vocational Behavior 68(1): 131-164. doi: 10.1016/j.jvb.2005.02.002.

Carlson, Dawn S., K. Michele Kacmar, and Larry J. Williams, 2000. 'Construction and Initial Validation of a Multidimensional Measure of WorkFamily Conflict.' Journal of Vocational Behavior 56(2): 249-276. doi: 10.1006/jvbe.1999.1713.

Casper, Wendy J., Lillian T. Eby, Christopher Bordeaux, Angie Lockwood, and Dawn Lambert, 2007. 'A Review of Research Methods in IO/OB Work-Family Research.' Journal of Applied Psychology 92(1): 28-43. doi: 10.1037/0021-9010.92.1.28.

Cheung, Gordon W. and Roger B. Rensvold, 2002. 'Evaluating Goodnessof-Fit Indexes for Testing Measurement Invariance.' Structural Equation Modeling. A Multidisciplinary Journal 9(2): 233-255. doi: 10.1207/S15328007SEM0902_5.

Demerouti, Evangelia, Arnold B. Bakker, Friedhelm Nachreiner, and Wilmar B. Schaufeli, 2001. 'The Job Demands-Resources Model of Burnout.' Journal of Applied Psychology 86(3): 499-512. doi: 10.1037/0021-9010.86.3.499.

Den Dulk, Laura, 2001. Work-Family Arrangements in Organisations. A CrossNational Study in The Netherlands, Italy, the United Kingdom, and Sweden. Amsterdam: Rozenberg.

den Dulk, Laura, 2005. 'Workplace Work-Family Arrangements. A Study and Explanatory Framework of Differences between Organizational Provisions in Different Welfare States.' In Poelmans, Steven A. Y., ed., Work and Family. An International Research Perspective, pp. 211-238. Mahwah, NJ: Erlbaum. 
den Dulk, Laura, Pascale Peters, and Erik Poutsma, 2012. 'Variations in Adoption of Workplace Work-Family Arrangements in Europe. The Influence of Welfare-State Regime and Organizational Characteristics.' International Journal of Human Resource Management 23(13): 2785-2808. doi: 10.1080/09585192.2012.676925.

Dikkers, Josje, Sabine Geurts, Laura den Dulk, Bram Peper, and Michiel Kompier, 2004. 'Relations among Work-Home Culture, the Utilization of Work-Home Arrangements, and Work-Home Interference.' International Journal of Stress Management 11(4): 323-345. doi: 10.1037/10725245.11.4.323.

Dikkers, Josje, Marloes van Engen, and Claartje Vinkenburg, 2010. 'Flexible Work. Ambitious Parents' Recipe for Career Success in The Netherlands.' Career Development International 15(6): 562-582. doi: $10.1108 / 13620431011084411$.

DiRenzo, Marco S., Jeffrey H. Greenhaus, and Christy H. Weer, 2011. 'Job Level, Demands, and Resources as Antecedents of Work-Family Conflict.' Journal of Vocational Behavior 78(2): 305-314. doi: 10.1016/j.jvb.2010.10.002.

Dreher, George F., 2003. 'Breaking the Glass Ceiling. The Effects of Sex Ratios and Work-Life Programs on Female Leadership at the Top.' Human Relations 56(5): 541-562. doi: 10.1177/0018726703056005002.

Drobnič, Sonja and Ana M. Guillén Rodríguez, 2011. 'Tensions Between Work and Home. Job Quality and Working Conditions in the Institutional Contexts of Germany and Spain.' Social Politics 18(2): 232-268. doi: 10.1093/sp/jxr008.

Drobnič, Sonja, Barbara Beham, and Patrick Präg, 2010. 'Good Job, Good Life? Working Conditions and Quality of Life in Europe.' Social Indicators Research 99(2): 205-225. doi: 10.1007/s11205-010-9586-7.

Eby, Lillian T., Wendy J. Casper, Angie Lockwood, Chris Bordeaux, and Andi Brinley, 2005. 'Work and Family Research in IO/OB. Content Analysis and Review of the Literature (1980-2002).' Journal of Vocational Behavior 66(1): 124-197. doi: 10.1016/j.jvb.2003.11.003.

Enders, Craig K. and Davood Tofighi, 2007. 'Centering Predictor Variables in Cross-Sectional Multilevel Models. A New Look at an Old Issue.' Psychological Methods 12(2): 121-138. doi: 10.1037/1082-989x.12.2.121.

Erikson, Robert and John H. Goldthorpe, 1992. The Constant Flux. A Study of Class Mobility in Industrial Societies. Oxford: Clarendon. 
Esping-Andersen, Gøsta, 1999. Social Foundations of Postindustrial Economies. Oxford: Oxford University Press. doi: 10.1093/0198742002.001.0001.

Ezzedeen, Souha R. and Paul M. Swiercz, 2007. 'Development and Initial Validation of a Cognitive-Based Work-Non-Work Conflict Scale.' Psychological Reports 100(3): 979-999. doi: 10.2466/pr0.100.3.979-999.

Fagan, Colette, 2003. Working-Time Preferences and Work-Life Balance in the EU. Some Policy Considerations for Enhancing the Quality of Life. Dublin: European Foundation for the Improvement of Living and Working Conditions.

Frone, Michael R., John K. Yardley, and Karen S. Markel, 1997. 'Developing and Testing an Integrative Model of the Work-Family Interface.' Journal of Vocational Behavior 50(2): 145-167. doi: https://doi.org/10.1006/jvbe.1996.1577.

Ganzeboom, Harry B. G. and Donald J. Treiman, 1996. 'Internationally Comparable Measures of Occupational Status for the 1988 International Standard Classification of Occupations.' Social Science Research 25(3): 201-239. doi: 10.1006/ssre.1996.0010.

Gelman, Andrew and Jennifer Hill, 2007. Data Analysis Using Regression and Multilevel/Hierarchical Models. Cambridge: Cambridge University Press. doi: 10.1017/CBO9780511790942.

Geurts, Sabine A. E., Toon W. Taris, Michiel A. J. Kompier, Josje S. E. Dikkers, Madelon L. M. Van Hooff, and Ulla M. Kinnunen, 2005. 'WorkHome Interaction from a Work Psychological Perspective. Development and Validation of a New Questionnaire, the SWING.' Work and Stress. An International Journal of Work, Health, and Organisations 19(4): 319-339. doi: 10.1080/02678370500410208.

Grandey, Alicia A., Bryanne L. Cordeiro, and Judd H. Michael, 2007. 'WorkFamily Supportiveness Organizational Perceptions. Important for the Wellbeing of Male Blue-Collar Hourly Workers?' Journal of Vocational Behavior 71(3): 460-478. doi: 10.1016/j.jvb.2007.08.001.

Greenhaus, Jeffrey H. and Tammy D. Allen, 2011. 'Work-Family Balance. A Review and Extension of the Literature.' In Quick, James Campbell and Lois E. Tetrick, eds., Handbook of Occupational Health Psychology, pp. 165183. Washington, DC: American Psychological Association, 2nd edition.

Greenhaus, Jeffrey H. and Nicholas J. Beutell, 1985. 'Sources of Conflict between Work and Family Roles.' Academy of Management Review 10(1): 76-88. doi: 10.5465/AMR.1985.4277352. 
Greenhaus, Jeffrey H. and Gary N. Powell, 2006. 'When Work and Family Are Allies. A Theory of Work-Family Enrichment.' Academy of Management Review 31(1): 72-92. doi: 10.5465/AMR.2006.19379625.

Hammer, Leslie B., Ellen Ernst Kossek, W. Kent Anger, Todd Bodner, and Kristi L. Zimmerman, 2011. 'Clarifying Work-Family Intervention Processes. The Roles of Work-Family Conflict and Family-Supportive Supervisor Behaviors.' Journal of Applied Psychology 96(1): 134-150. doi: 10.1037/a0020927.

Hanson, Ginger C., Leslie B. Hammer, and Cari L. Colton, 2006. 'Development and Validation of a Multidimensional Scale of Perceived Work-Family Positive Spillover.' Journal of Occupational Health Psychology 11(3): 249-265. doi: 10.1037/1076-8998.11.3.249.

Hausmann, Ricardo, Laura D. Tyson, and Saadia Zahidi, 2011. The Global Gender Gap Report 2011. Geneva: World Economic Forum.

Henly, Julia R. and Susan J. Lambert, 2005. 'Nonstandard Work and Child Care Needs of Low-Income Parents.' In Bianchi, Suzanne M., Lynne M. Casper, and Rosalind Berkow King, eds., Work, Family, Health, and Wellbeing, pp. 473-492. Mahwah, NJ: Erlbaum. doi: 10.4324/9781410613523.

Kalliath, Thomas, Jeffrey H. Greenhaus, Paula Brough, Oi-ling Siu, Michael O'Driscoll, and Jerry Marmen, 2012. Is Work-Life Balance a Distinct Construct from Work-Family Conflict and Enrichment? A Longitudinal Evaluation. New York: Paper presented at the Inaugural Conference of the Work and Family Researchers Network Conference.

Kossek, Ellen Ernst, Boris B. Baltes, and Russell A. Matthews, 2015. 'How Work-Family Research Can Finally Have an Impact in Organizations.' Industrial and Organizational Psychology 4(3): 352-369. doi: 10.1111/j.17549434.2011.01353.x.

Kovacheva, Siyka, Anneke van Doorne-Huiskes, and Timo Anttila, 2011. 'The Institutional Context of the Quality of Life.' In Bäck-Wiklund, Margareta, Tanja van der Lippe, Laura den Dulk, and Anneke van DoorneHuiskes, eds., Quality of Life and Work in Europe. Theory, Practice, and Policy, pp. 32-54. Houndsmills, Basingstoke: Palgrave Macmillan. doi: 10.1057/9780230299443_3.

Lambert, Susan J. and Anna Haley-Lock, 2004. 'The Organizational Stratification of Opportunities for Work-Life Balance. Addressing Issues of Equality and Social Justice in the Workplace.' Community, Work, and Family 7(2): 179-195. doi: 10.1080/13668880042000245461. 
Lambert, Susan J. and Elaine Waxman, 2005. 'Organizational Stratification. Distributing Opportunities for Balancing Work and Personal Life.' In Kossek, Ellen Ernst and Susan J. Lambert, eds., Work and Life Integration. Organizational, Cultural, and Individual Perspectives, pp. 103-126. Mahwah, NJ: Erlbaum. doi: 10.4324/9781410611529.

Lawrence, Thomas B. and Vivien Corwin, 2003. 'Being There. The Acceptance and Marginalization of Part-Time Professional Employees.' Journal of Organizational Behavior 24(8): 923-943. doi: 10.1002/job.229.

Lewis, Suzan and Janet Smithson, 2001. 'Sense of Entitlement to Support for the Reconciliation of Employment and Family Life.' Human Relations 54(11): 1455-1481. doi: 10.1177/00187267015411003.

Lyness, Karen S. and Marcia Brumit Kropf, 2005. 'The Relationships of National Gender Equality and Organizational Support with Work-Family Balance. A Study of European Managers.' Human Relations 58(1): 33-60. doi: 10.1177/0018726705050934.

Major, Debra A., Thomas D. Fletcher, Donald D. Davis, and Lisa M. Germano, 2008. 'The Influence of Work-Family Culture and Workplace Relationships on Work Interference with Family. A Multilevel Model.' Journal of Organizational Behavior 29(7): 881-897. doi: 10.1002/job.502.

McGinnity, Frances and Emma Calvert, 2009. 'Work-Life Conflict and Social Inequality in Western Europe.' Social Indicators Research 93(3): 489-508. doi: $10.1007 / \mathrm{s} 11205-008-9433-2$.

Michel, Jesse S., Lindsey M. Kotrba, Jacqueline K. Mitchelson, Malissa A. Clark, and Boris B. Baltes, 2011. 'Antecedents of Work-Family Conflict. A Meta-Analytic Review.' Journal of Organizational Behavior 32(5): 689-725. doi: 10.1002/job.695.

Milliken, Francis J. and Linda M. Dunn-Jensen, 2005. 'The Changing Time Demands of Managerial and Professional Work. Implications for Managing the Work-Life Boundary.' In Kossek, Ellen Ellen and Susan J. Lambert, eds., Work and Life Integration. Organizational, Cultural, and Individual Perspectives, pp. 43-59. Mahwah, NJ: Erlbaum. doi: 10.4324/9781410611529.ch3.

Mills, Melinda, Patrick Präg, Flavia Tsang, Katia Begall, James Derbyshire, Laura Kohle, Céline Miani, and Stijn Hoorens, 2014a. Use of Childcare Services in the EU Member States and Progress Towards the Barcelona Targets. Brussels: European Commission DG Justice. doi: 10.2838/54302.

Mills, Melinda, Flavia Tsang, Patrick Präg, Kai Ruggeri, Céline Miani, and Stijn Hoorens, 2014b. Gender Equality in the Workforce. Reconciling Work, 
Private, and Family Life in Europe. Brussels: European Commission DG Justice. doi: 10.2838/54302.

Peper, Bram, Josje Dikkers, Claartje Vinkenburg, and Marloes van Engen, 2011. 'Causes and Consequences of the Utilization of Work-Life Policies by Professionals. 'Unconditional Supervisor Support Required'.' In Kaiser, Stephan, Max Josef Ringlstetter, Doris Ruth Eikhof, and Miguel Pina e Cunha, eds., Creating Balance? International Perspectives on the Work-Life Integration of Professionals, pp. 225-250. Berlin: Springer. doi: 10.1007/978-3-642-161995_13.

Pitt-Catsouphes, Marcie, 2002. 'Family-Friendly Workplace.' In Kossek, Ellen and Marcie Pitt-Catsouphes, eds., Work and Family Encyclopedia. Chestnut Hill, MA: Sloan Work and Family Research Network.

Poelmans, Steven and Khatera Sahibzada, 2004. 'A Multi-Level Model for Studying the Context and Impact of Work-Family Policies and Culture in Organizations.' Human Resource Management Review 14(4): 409-431. doi: 10.1016/j.hrmr.2004.10.003.

Präg, Patrick, Maria das Dores Guerreiro, Jouko Nätti, Michael Brookes, and Laura den Dulk, 2011. 'Quality of Work and Quality of Life of Service Sector Workers. Cross-National Variations in Eight European Countries.' In BäckWiklund, Margareta, Tanja Van der Lippe, Laura Den Dulk, and Anneke Van Doorne-Huiskes, eds., Quality of Work and Life. Theory, Practice, and Policy, pp. 77-94. Basingstoke: Palgrave Macmillan. doi: 10.1057/9780230299443_5.

Präg, Patrick and Melinda Mills, 2014. Family-Related Working Schedule Flexibility across Europe. Cambridge: Rand Corporation. doi: 10.2838/54302.

Raudenbush, Stephen W. and Anthony S. Bryk, 2002. Hierarchical Linear Models. Applications and Data Analysis Methods. Thousand Oaks, CA: Sage, 2nd edition.

Reindl, Cornelia U., Stephan Kaiser, and Martin L. Stolz, 2011. 'Integrating Professional Work and Life. Conditions, Outcomes and Resources.' In Kaiser, Stephan, Max Josef Ringlstetter, Doris Ruth Eikhof, and Miguel Pina e Cunha, eds., Creating Balance? International Perspectives on the Work-Life Integration of Professionals, pp. 3-26. Berlin: Springer. doi: 10.1007/978-3642-16199-5_1.

Riordan, Christine M. and Robert J. Vandenberg, 1994. 'A Central Question in Cross-Cultural Research. Do Employees of Different Cultures Interpret Workrelated Measures in an Equivalent Manner?' Journal of Management 20(3): 643-671. doi: 10.1177/014920639402000307. 
Sanne, Bjarte, Steffen Torp, Arnstein Mykletun, and Alv A. Dahl, 2005. 'The Swedish Demand-Control-Support Questionnaire (DCSQ). Factor Structure, Item Analyses, and Internal Consistency in a Large Population.' Scandinavian Journal of Social Medicine 33(3): 166-174. doi: 10.1080/14034940410019217.

Schieman, Scott and Paul Glavin, 2011. 'Education and Work-Family Conflict. Explanations, Contingencies, and Mental Health Consequences.' Social Forces 89(4): 1341-1362. doi: 10.1093/sf/89.4.1341.

Schieman, Scott, Yuko Kurashina Whitestone, and Karen Van Gundy, 2006. 'The Nature of Work and the Stress of Higher Status.' Journal of Health and Social Behavior 47(3): 242-257. doi: 10.1177/002214650604700304.

Spector, Paul E., 2002. 'Research Methods in Industrial and Organizational Psychology. Data Collection and Data Analysis with Special Consideration to International Issues.' In Anderson, Neil, Deniz S. Ones, Handan Kepir Sinangil, and Chockalingam Viswesvaran, eds., Handbook of Industrial, Work, and Organizational Psychology, volume 1 (Personnel Psychology), pp. 10-26. London: Sage. doi: 10.4135/9781848608320.n2.

Stone-Romero, Eugene F. and Patrick J. Rosopa, 2007. 'The Relative Validity of Inferences About Mediation as a Function of Research Design Characteristics.' Organizational Research Methods 11(2): 326-352. doi: 10.1177/1094428107300342.

Tausig, Mark and Rudy Fenwick, 2001. 'Unbinding Time. Alternate Work Schedules and Work-Life Balance.' Journal of Family and Economic Issues 22(2): 101-119. doi: 10.1023/A:1016626028720.

Tåhlin, Michael, 2007. 'Class Clues.' European Sociological Review 23(5): 557572. doi: $10.1093 / \mathrm{esr} / \mathrm{jcm} 019$

Thomas, Linda Thiede and Daniel C. Ganster, 1995. 'Impact of FamilySupportive Work Variables on Work-Family Conflict and Strain. A Control Perspective.' Journal of Applied Psychology 80(1): 6-15. doi: 10.1037/00219010.80.1.6.

Thompson, Cynthia A., Laura L. Beauvais, and Karen S. Lyness, 1999. 'When Work-Family Benefits Are Not Enough. The Influence of WorkFamily Culture on Benefit Utilization, Organizational Attachment, and Work-Family Conflict.' Journal of Vocational Behavior 54(3): 392-415. doi: 10.1006/jvbe.1998.1681.

UNDP, 2007. Human Development Report 2007/2008. Fighting Climate Change. Human Solidarity in a Divided World. Houndmills, Basingstoke: Palgrave Macmillan. doi: 10.1057/9780230598508. 
— 2010. Human Development Report. The Real Wealth of Nations. Pathways to Human Development. Houndmills, Basingstoke: Palgrave Macmillan.

Valcour, Monique P., 2007. 'Work-Based Resources as Moderators of the Relationship between Work Hours and Satisfaction with Work-Family Balance.' Journal of Applied Psychology 92(6): 1512-1523. doi: 10.1037/00219010.92.6.1512.

van Oorschot, Wim, 2006. 'The Dutch Welfare State. Recent Trends and Challenges in Historical Perspective.' European Journal of Social Security 8(1): 57-76. doi: 10.1177/138826270600800104.

Visser, Jelle, 2002. 'The First Part-Time Economy in the World. A Model to Be Followed?' Journal of European Social Policy 12(1): 23-42. doi: 10.1177/0952872002012001561.

Voydanoff, Patricia, 2005a. 'Toward a Conceptualization of Perceived Work-Family Fit and Balance. A Demands and Resources Approach.' Journal of Marriage and Family 67(4): 822-836. doi: 10.1111/j.17413737.2005.00178.x.

_ 2005b. 'Work Demands and Work-to-Family and Family-to-Work Conflict. Direct and Indirect Relationships.' Journal of Family Issues 26(6): 707-726. doi: $10.1177 / 0192513 X 05277516$.

Weigt, Jill M. and Catherine Richards Solomon, 2008. 'Work-Family Management among Low-wage Service Workers and Assistant Professors in the USA. A Comparative Intersectional Analysis.' Gender, Work, and Organization 15(6): 621-649. doi: 10.1111/j.1468-0432.2008.00419.x. 